\title{
Caminhos para a pesquisa sociológica
}

\author{
Paths towards sociological research
}

\section{Ana Carolina Trevisan Camilo Ferreira ${ }^{a}$, Allan Herison Ferreira ${ }^{b}$, Roberta de Oliveira Soares ${ }^{c}$}

Paugam, Serge (Org.) A pesquisa sociológica. Petrópolis: Editora Vozes, 2015.

\section{ASPECTOS GERAIS DA OBRA}

O livro A pesquisa sociológica, publicado em português em 2015 pela Editora Vozes para a Coleção Sociologia, com tradução de Francisco Morás, é uma obra coletiva sobre a prática de pesquisa em sociologia, coordenada pelo sociólogo francês Serge Paugam ${ }^{1}$ e lançada em 2010 sob o título L'enquête sociologique. Sua estrutura reflete um curso sob a forma de seminário ministrado na École des Hautes Études en Sciences Sociales (EHESS), liderado por Paugam e Cyril Lemieux, entre 2005 e 2009.

Cada capítulo ou lição traz a contribuição de outros dezoito autores - em sua maioria participantes desse mesmo seminário - que dividem com o leitor suas experiências de campo, apontamentos e conteúdos apresentados em palestras e em sala de aula sobre o processo de produção de conhecimento com base na pesquisa empírica em sociologia. Trata-se, portanto, não de um manual de metodologia de pesquisa sobre uma abordagem específica, mas de uma oportunidade de aprendizado e contato com um conjunto das técnicas e métodos mais usados na pesquisa empírica. Na medida em que se avança em cada lição, é possível perceber a preocupação própria ao autor com a forma de apresentar cada conteúdo e de envolver o "leitor-aluno", de modo a supri-lo com instrumentos indispensáveis para a obtenção do que Paugam definiu como "habilidade sociológica”: um conhecimento preciso sobre as diversas técnicas disponíveis na disciplina, aliado ao discernimento para escolher a melhor técnica de acordo com o tema-alvo da pesquisa.

a Graduada em Psicologia (Universidade Mackenzie) e Ciências Sociais pela Universidade de São Paulo. Atualmente, é mestranda em Sociologia pela Universidade de São Paulo e membro do ImaRgens/LAPS - Iniciativa para o Audiovisual em Ciências Sociais.

b Possui graduação em Ciências Sociais pela Universidade de São Paulo. Mestrando em Sociologia na mesma instituição e membro do ImaRgens/LAPS - Iniciativa para o Audiovisual em Ciências Sociais.

c Graduada em Ciências Sociais pela Universidade de São Paulo, atualmente é mestranda em Sociologia na mesma instituição.

1 Serge Paugam é Diretor de Estudos da EHESS - École des Hautes Études en Sciences Sociales, Paris, França. No primeiro semestre de 2016, apresentou o curso Work and Social Bonds in the twenty-first century capitalism como professor convidado do Programa de Pós-Graduação em Sociologia da Universidade de São Paulo. 
O percurso proposto pelo coordenador do curso e do livro permite ao leitor compreender as especificidades da pesquisa sociológica, bem como conhecer uma ampla gama de técnicas de coleta de dados, diferentes modos de apresentação dos resultados de pesquisa e métodos de análise. São dicas práticas, relatos de experiências, respostas a certos dilemas e reflexões sobre o engajamento e a função do sociólogo em seu meio, dentre outras questões importantes para a composição de um bom repertório, capaz de elevar as chances de sucesso na realização do trabalho de pesquisa em sociologia e em outras áreas das ciências sociais.

O livro é dividido em quatro partes, que Paugam define em sua introdução como elementos essenciais de uma pesquisa sociológica: "A postura sociológica", "As técnicas de pesquisa", "Os métodos de análise" e "A restituição de resultados". Essas etapas, além de conduzirem os leitores à postura que se espera de um pesquisador, desde as técnicas de que dispõem para viabilizarem seus projetos, até os métodos de análise dos dados coletados e de como melhor apresentá-los, abrem também generosas "janelas" que permitem um contato inicial com os temas e campos de trabalho visitados ou conduzidos pelos autores da obra.

A leitura do livro não precisa, necessariamente, percorrer a ordem dos capítulos, embora a sequencialidade, em especial da primeira parte, permita aos interessados ter acesso a uma boa revisão de conceitos abordados nas disciplinas de métodos de pesquisa em sociologia dos cursos de graduação e pós-graduação, além de uma aproximação, ou reaproximação, às questões metodológicas que cercam a prática do pesquisador. As demais partes podem ser lidas seletivamente de acordo com o tema de interesse da pesquisa que se almeja conduzir. Persiste, no entanto, a recomendação da leitura de todas as lições propostas, especialmente quando se procura a introdução dos temas a novos pesquisadores.

\section{ASPECTOS GERAIS SOBRE REFERÊNCIAS UTILIZADAS NA OBRA E $O$ UNIVERSO DE PESQUISA DE SEUS COLABORADORES}

Na obra em questão, a relação entre os autores clássicos da disciplina e as pesquisas mais recentes ocorre de modo equilibrado, dando aos leitores um panorama do que os autores dos capítulos estão produzindo em seus respectivos trabalhos de pesquisa. Tem-se contato com técnicas avançadas de pesquisa empírica, aplicadas e desenvolvidas por pesquisadores de diferentes institutos e equipes ligadas à EHESS. São alguns destes grupos: a Equipe de Pesquisa sobre Desigualdades Sociais (ERIS), dirigida por Paugam, e que conta também com a colaboração de autores de capítulos do livro, dentre eles Cécile van de Velde, 
Florence Maillochon, Isabelle Parizot, Jean-Marie Firdion e Pascale Dietrich; ${ }^{2}$ e outros institutos, como o Laboratório Interdisciplinar de Estudos da Reflexividade (LIER), o Centro de Estudos Sociológicos e Políticos Raymond Aron (CESPTRA), o Centro Maurice Halbwachs (CMH), o Centro de Estudos dos Movimentos Sociais (CEMS), o Centro Europeu de Sociologia (CSE) e a Escola Normal Superior (ENS).

Cada capítulo-lição oferece cuidadosas orientações e indicações de caminhos teóricos e práticos a serem tomados do ponto de vista metodológico e técnico. Permite, também, que o leitor se familiarize com o modo pelo qual este ou aquele professor busca aplicar tais conhecimentos em suas próprias áreas e, ainda, que se tenha contato com as principais referências por eles mobilizadas em suas atividades de pesquisa. Reunir material de aulas e seminários de pesquisadores ligados à EHESS permite que o leitor tenha, em um único volume, além dos conceitos e técnicas que formam o eixo central do livro, um panorama da pesquisa realizada nessa instituição francesa, dando a sensação de leitura leve, como a de uma revista.

Desde o primeiro capítulo é possível perceber o tom didático e minucioso do livro, que pode ser visto tanto como uma série de degraus a serem galgados antes de se lançar em uma pesquisa, quanto como mapa com definições do papel do sociólogo e dos objetivos que lhe são pertinentes, a serem esquadrinhados de acordo com os objetivos do jovem pesquisador. Encontram-se, ainda, orientações sobre o que evitar e o que esperar na etapa de concepção do objeto de pesquisa, bem como instruções detalhadas sobre como elaborar um projeto - tudo isso permeado por excertos de obras de autores clássicos que ilustram pontos específicos, seguidos da análise dos colaboradores do livro. Nessa medida, tem-se a impressão clara de se estar sentado à frente do professor experiente que parece intuir sobre as angústias de seus alunos e antecipar as suas dúvidas. Já o pesquisador mais experiente poderá ver expressos no livro dilemas semelhantes aos de suas vivências no campo.

\section{CONTEÚDO E ORGANIZAÇÃO DAS PARTES E CAPÍTULOS DO LIVRO}

A primeira parte, intitulada $A$ postura sociológica, traz três lições e discute aspectos fundamentais relacionados à escolha do objeto e à definição do problema de pesquisa, além de observações sobre as alternativas e limites com os quais os sociólogos se deparam quando constroem ou delimitam seu objeto de estudo, processo que Serge Paugam chama de modo de objetivação. Esse bloco se estende como um tapete vermelho a alunos e jovens pesquisadores que, na busca pela

2 Passaram também pelo ERIS outros colaboradores da obra, como Mari Loison, Manoela Roupnel, Mirna Safi e Sébastien Chauvir. 
especialização em métodos e técnicas específicos, correm o risco de deixar em segundo plano elementos centrais da pesquisa sociológica. Um exemplo de como a linguagem do livro busca facilitar a aproximação com o leitor é dada por Cyril Lemieux, na lição dois. Nela, o autor afirma que o sociólogo deve formular um enigma que demanda uma resposta empírica, com o objetivo de "tornar enigmático o mundo social que habitamos" (p.35). Mais do que apresentar cuidados técnicos e metodológicos, em toda a primeira parte é possível observar verdadeiras dicas de como tornar o trabalho de pesquisa mais interessante ao público que hoje extrapola os limites do ambiente acadêmico.

A segunda parte traz sete lições sobre as técnicas de pesquisa e suas aplicações na prática. As lições desse bloco podem ajudar o pesquisador a buscar uma melhor relação entre sua questão sociológica e os sujeitos e materiais de seu campo, evitando, por exemplo, que a falta de cuidado e planejamento nos diferentes momentos de sua atividade de pesquisa acabem por prejudicar os resultados finais do trabalho. Nesse sentido, na lição quatro, "Construir uma amostra”, Jean-Marie Firdion lembra que as pesquisas estatísticas são hoje fatores que causam grande impacto e que exercem muita influência sobre o público que delas se abastece nas mais diversas áreas do conhecimento formal e informal. $\mathrm{O}$ cuidado com a qualidade do material que se produz por meio dos métodos estatísticos precisa, portanto, ser redobrado ao longo de todo o processo, desde os momentos iniciais de planejamento da pesquisa e de sua operacionalização, até a entrega de seu resultado, com especial atenção para a etapa de análise, que é quando se tende a fazer uso dos resultados para construir generalizações.

A terceira parte explora métodos de análise do material coletado em campo. Na lição onze, "O raciocínio etnográfico”, Stéphane Beaud e Florence Weber defendem o uso da etnografia, que elas mesmas classificam como sendo um método legitimado em antropologia e etnologia, mas que ainda encontra resistência na sociologia. As autoras do capítulo enfatizam a importância da etnografia para a pesquisa sociológica, uma vez que ela possibilita ao pesquisador não só se ater a apresentar aspectos de caráter holista - termo destacado pelas autoras ao referirem-se tanto aos modelos da vertente quantitativa durkheimiana, quanto da vertente estrutural-funcionalista marxista (p.188) -, mas também produzir narrativas que ajudem a aproximar o público dos resultados de sua pesquisa. A oportunidade de contato com o raciocínio etnográfico da lição onze não só permite que a abordagem etnográfica possa ser melhor empregada no trabalho de pesquisa, mas também ajuda a calibrar a sensibilidade dos leitores em relação à abordagem quantitativa trabalhada na lição doze, “O raciocínio estatístico em sociologia”. Nesse 
capítulo, Marion Selz demonstra que a estatística precisa ser melhor compreendida para ser melhor utilizada. A partir disso, a autora aconselha tratar o tema "sem fórmulas matemáticas” (p.202), voltando-se especialmente para os cuidados com o processo de planejamento e preparação para o uso desse tipo de técnica, como a construção dos dados e a elaboração de questionários, execução das estatísticas e interpretação dos resultados gerados. Se, por um lado, os capítulos que constituem essa terceira parte trazem o mesmo tom de acolhimento ao jovem pesquisador ou ao "leitor-aluno" visto nas duas primeiras partes, por outro, o trazem de maneira mais diluída, permitindo ao mesmo tempo uma maior objetividade no modo de abordar os métodos de análise empregados na pesquisa sociológica. Isso pode ser observado, por exemplo, na lição dezesseis, "Interpretar as redes sociais”, na qual Olivier Godechot, a partir de um mesmo exemplo, apresenta técnicas de análise das redes sociais: afinal, como ler um gráfico de rede e compreender as estruturas topológicas da rede, e como analisar a formação das relações e considerar os efeitos da rede sobre os comportamentos? Isso permite que sejam aprofundadas questões abordadas em momento anterior do livro, como no capítulo nove (parte II), em que Florence Maillochon defende o uso da análise de redes.

A quarta e última parte, "A restituição dos resultados", apresenta as últimas três lições do livro e se propõe a refletir sobre a escrita sociológica e, por conseguinte, sobre a comunicação decorrente da produção sociológica. Autores de capítulos de partes precedentes reaparecem, aqui, para apresentar os cuidados aos quais o pesquisador deve estar atento na etapa final da realização de seu projeto. Não adotar uma postura omissa em relação às pessoas com as quais conviveu e se relacionou durante seu trabalho de campo é uma das preocupações apresentadas nesta parte do livro. Outro aspecto destacado é a busca pelo máximo de precisão em sua escrita, adotando a postura de primar pela clareza, conforme se observa no capítulo dezoito, "A escrita Sociológica”. Já no capítulo dezenove, "O sociólogo e as mídias", Cécile van de Velde mostra que o trabalho, em prol de maior qualidade no uso de informações sobre a sociedade, gera efeitos não somente em forma de resultados acadêmicos, mas também em melhorias na vida prática das pessoas. A autora considera que a mídia, nas últimas décadas, tem tido cada vez maior importância na prática sociológica. O sociólogo pode ser considerado perito pela mídia e participar não apenas da esfera acadêmica, mas também da midiática. Nesse sentido, do ponto de vista ético, van de Velde defende a importância da reflexão feita pelo sociólogo não só enquanto cientista, mas também como cidadão que produz conhecimento para além das fronteiras acadêmicas, atuando, assim, para uma melhoria na qualidade dos debates públicos. Esta quarta parte do livro 
apresenta aos leitores possibilidades de atuação dos pesquisadores em ciências sociais que nem sempre são observadas ou levadas adiante. $\mathrm{O}$ alerta feito pelos autores em relação a esses "pontos cegos" do trabalho de pesquisa soam como um convite para que jovens pesquisadores ocupem espaços pouco explorados e que contribuam na expansão dos atuais limites do campo de atuação em pesquisa sociológica.

É possível afirmar que se trata de uma obra de muitas urgências, mas que são tratadas numa levada que respeita o perfil e o ritmo do público a que se destina. A edição publicada pela Editora Vozes tem uma boa impressão e de fácil manuseio e leitura - talvez seja prudente comentar que há erros tipográficos na obra, mas que não atrapalham a leitura do livro, assim como não foram observados trechos que apresentassem maiores dificuldades de compreensão que pudessem levar a um questionamento ou desabono da tradução da obra. O texto frequentemente nos exorta, afirmando que urge que se proceda "deste" ou "daquele" modo, enfatizando necessidades e riscos reservados à pesquisa sociológica; porém, por outro lado, não se omite em apresentar possibilidades revigorantes e os macetes de trilhas já pisadas por quem experimentou trajetórias similares às que os leitores estão enfrentando ou estão prestes a enfrentar. Os autores demonstram, ao longo da obra, estar cientes de que costuma ser complexa a passagem dos conhecimentos teórico-metodológicos para a prática efetiva de pesquisa. Isso pode ajudar a explicar as ricas passagens que compartilham sobre suas trajetórias, as quais poderão proporcionar aos leitores mais atentos o aproveitamento dessas orientações sutis com o mesmo respeito que tendem a ter por modelos, métodos e técnicas já consagradas, que também são apresentadas neste livro.

Recebido para publicação em: 30/06/2016. Aceito para publicação em: 05/09/2016. 